yields, so the crop response model cannot easily be tested from historical documentation.

Changes in pest populations further complicate the picture, as increased global temperatures will generally lead to higher levels of pest infestation in agriculture. Migratory pests that currently survive the winter in lower-latitude refugia, such as the sunflower moth and the corn earworm, may benefit from extended winter ranges and possibly also from easier transportation from one region to another with new atmospheric circulation patterns.

As well as considering the total global yield of agricultural production, Rosenzweig and Hillel investigate regional effects in relation to local environmental and economic conditions. Modelling suggests that the greatest potential increases in agricultural production will occur in Canada and Russia, with the strongest negative trends in equatorial regions, particularly Central America and South-East Asia. But the outcome is dependent on the extent of the temperature rise and, if the increase in global temperature reaches $4{ }^{\circ} \mathrm{C}$, the impact could be negative throughout the world.

The authors use Egypt and the United States as case studies to examine the likely impact of global change on agriculture in specific areas. They demonstrate the flexibility of the United States in responding to new conditions and regard its agriculture as relatively robust but perhaps sensitive to the anticipated variability of a future climate. Egypt, which depends on irrigation for its agriculture, should be regarded as at risk. A rise in sea level would cause greater erosion and salination of the valuable lands of the Nile delta, and a rise in temperature and evaporation can have only negative effects. Much will depend on Egypt's efficiency in the use of its agricultural land and its limited water resources.

The authors conclude that uncertainties abound. They are cautious in their predictions, but their book must rank as the most integrated, informative and accessible account of the complexities of this subject. $\square$ Peter D. Moore is in the Division of Life Sciences, King's College, Campden Hill Road, London W8 7AH, UK.

\section{Stress points}

\section{A Mood Apart: A Thinker's Guide to Emotion and its Disorders}

by Peter C. Whybrow

HarperCollins/Picador: 1998. Pp. 340.

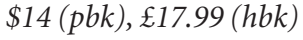

\section{Stuart Sutherland}

As anyone working in the field will tell you, our knowledge of the neural correlates of manic depression has vastly increased in recent years. We now have at least 20 drugs that alleviate depression and several that both reduce mania and have a prophylactic effect on bipolar manic depression. We know - or think we know - which neurotransmitters are involved in affective illness. We also know much about the hormonal and neurotransmitter responses to stress, which are often, although by no means always, a precipitating factor in mental illness. And we have developed a psychological treatment for depression that actually works.

But despite these advances, a great deal remains opaque. The prototypes of most of the drugs were discovered by chance. We have no idea of the detailed neural pathways governing mood. We are uncertain of the aberrations in transmitter function that result in depression or mania. And we do not understand why stress should sometimes be beneficial, sometimes disastrous.

In his account of affective disorders, Peter C. Whybrow emphasizes the importance of stress. He argues that the physical threats with which the brain has evolved to cope were transient, whereas stress induced by social factors can be long-lasting and hence damaging. He repeatedly claims that homeostasis is disorganized by stress. True, the brain contains an incredible number of homeostatic mechanisms but, unless the way these mechanisms are affected can be specified, the use of the term "homeostasis" serves only to conceal our ignorance.

Although Whybrow knows his way around the brain's biochemistry, he is sometimes rather dogmatic. Perhaps he thought it would tax the reader too heavily if he mentioned explanations antithetic to his own. For example, he believes that depression is in part caused by underactivity in the monoamine systems, particularly that of dopamine, but many believe that overactivity is the cause. The drugs that ameliorate depression take several weeks to work and their efficacy may depend on a reduction of postsynaptic receptors in response to a sharp increase in amine activity. Moreover, Whybrow is sometimes cavalier with facts. He writes "Prozac affects only serotonin": in reality, it affects several neurotransmitters, and is the least selective of all the serotoninspecific reuptake inhibitors.

Unfortunately, the book goes more seriously awry when it deals with the psychological aspects of mood. The account of cognitive therapy is unsatisfactory. Whybrow believes that depression is associated with an "inaccurate" view of the world and of oneself, a view that is gloomier than is justified. In reality, the depressive's views are more accurate than those of normal people. The fact is - perhaps not surprisingly in this vale of tears - that people can be happy only if they are unrealistically optimistic. Again, he asserts that losing a mother or having a disturbed childhood can lead to depression in later life, but this is at best contentious.
Indeed, one authority recently wrote that the influence of child abuse on adult personality was "barely detectable".

The book has a rather ponderous style. For example, Whybrow writes of the action potential: "This efficient architectural innovation is essential to the increased speed of signalling that is a key element of survival behaviour", a statement that could have been made using half the number of words.

Whybrow follows current fashion by larding the text with anecdotes about himself, his friends and his patients. The inclusion of such largely irrelevant material is an insult to readers, as it assumes they cannot concentrate on a serious exposition without being constantly diverted by the human touch.

Having been rather critical, I should confess an interest: I am myself about to publish a book on mental illness, some of which overlaps with Whybrow's. I approached his book with the highest expectations, based on his eminence, and maybe I have overreacted to my disappointment; other readers may appreciate it more. Whybrow is extremely learned, as shown by the 70 pages of references and notes, which - at least for me - made considerably better reading than the text. Moreover, from time to time he makes some good points, for example by insisting that depression is not akin to sadness. And those of a more literary disposition may well enjoy the mixture of fact, speculation and emotional tales, some of which might make moving short stories.

Stuart Sutherland is at the Laboratory of Experimental Psychology, University of Sussex, Falmer, Brighton BN1 9QG, UK.

\section{New Journals}

This year, Nature's annual new journals review supplement will appear in the issue of 10 September. Publishers and learned societies are invited to submit journals for review, as well as details of any eligible electronic journals, taking note of the following criteria:

- Journals must have first appeared during or after June 1996 and issued at least four separate numbers by the end of May 1998. - Journals covering any aspect of science are eligible, although those dealing with clinical medicine and pure mathematics are excluded, as are newsletters and publications of abstracts.

- Frequency of publication must be at least three times a year.

- The main language is English.

- Deadline for submission is 5 June.

Please send at least four different issues (the first, the most recent and any two others) of each eligible title, together with full details of subscription rates, to: Peter Tallack, Nature, Porters South, Crinan Street, London N1 9XW, UK. Tel: +44 (0)171 843 4567. e-mail: p.tallack@nature.com 